\title{
Source process of the 1923 Kanto earthquake inferred from historical geodetic, teleseismic, and strong motion data
}

\author{
Reiji Kobayashi and Kazuki Koketsu \\ Earthquake Research Institute, University of Tokyo, 1-1-1 Yayoi, Bunkyo-ku, Tokyo 113-0032, Japan
}

(Received July 20, 2004; Revised February 22, 2005; Accepted March 1, 2005)

\begin{abstract}
The historical geodetic and teleseismic data are jointly inverted for the rupture process of the 1923 Kanto earthquake together with the strong motion data recently discovered. The resultant slip distribution shows two asperities (areas of large slips) on the fault plane with a total seismic moment of $1.1 \times 10^{21} \mathrm{Nm}\left(\mathrm{M}_{w} 8.0\right)$. The asperity in the shallow central portion of the fault is larger with maximum slip of approximately $10 \mathrm{~m}$ than the one in the hypocentral region. The recovered slip functions indicate that the initial slip was abrupt in the hypocentral asperity, though it was gradual in the larger asperity. The major discrepancies between the observations and synthetics are attributed to volcanic activities and the 3-D structure of the Kanto Basin. We compare the slip and aftershock distributions and also discuss the relation of the asperities to silent earthquakes.
\end{abstract}

Key words: The 1923 Kanto earthquake, source process, asperity.

\section{Introduction}

The September 1, 1923, Kanto earthquake is one of the most devastating earthquakes in history, causing severe damage and more than 100,000 fatalities in the Tokyo metropolitan area. This earthquake is an interplate event along the Sagami trough where the Philippine Sea plate is subducting beneath a continental plate (Fig. 1). Geomorphological studies suggested that similar great earthquakes have recurred along the Sagami trough during at least the last 6000 years (e.g., Sugimura and Naruse, 1954; Matsuda et al., 1978). Therefore, it is important to understand the detailed source process of the 1923 Kanto earthquake even for the prediction of the strong ground motions from a great future earthquake.

Many seismological and geodetical studies have been carried out for this earthquake. Kanamori and Miyamura (1970) located its hypocenter around the base of the Izu Peninsula from $P$-wave arrival times. Kanamori (1971) determined the focal mechanism to be right-lateral reverse faulting on a fault plane striking $\mathrm{N} 70^{\circ} \mathrm{W}$ from $P$-wave polarity data and the seismic moment to be $7.6 \times 10^{20} \mathrm{Nm}$ $\left(\mathrm{M}_{w}\right.$ 7.9) from surface wave amplitudes. Matsu'ura et al. (1980) and Matsu'ura and Iwasaki (1983) applied an inversion method to the geodetic data to obtain the fault parameters. Their models are consistent with the above focal mechanism by Kanamori (1971). The geodetic and teleseismic data were simultaneously inverted by Wald and Somerville (1995). Their solution shows two asperities (areas of large slips), one near the hypocenter and another shallower in the southeast of the first.

Recently, engineering seismologists (e.g., Yokota et al.,

Copy right(C) The Society of Geomagnetism and Earth, Planetary and Space Sciences (SGEPSS); The Seismological Society of Japan; The Volcanological Society of Japan; The Geodetic Society of Japan; The Japanese Society for Planetary Sciences; TERRAPUB.
1989; Takemura et al., 1994) have retrieved some regional seismograms from all over Japan, or restored clipped strong motion records observed at Tokyo. We combined these strong motion data with the teleseismic and geodetic data, and applied a joint inversion method to them for a detailed image of the source process.

\section{Data}

The geodetic and teleseismic datasets are the almost same as those of Wald and Somerville (1995). The Military Land Survey (1930) conducted leveling and triangulation for preseismic (1884-1898, 1884-1899) and postseismic periods (1923-1927, 1924-1925). The horizontal and vertical geodetic displacements caused by the 1923 Kanto earthquake were obtained from comparisons of the preseismic and postseismic measurements. The horizontal displacements were revised by Sato and Ichihara (1971), so we use their revised displacements. The vertical displacements and station coordinates were read from a map of the Military Land Survey (1930). These horizontal and vertical displacements are shown in Fig. 2, where we can find two zones of large vertical displacements and relate them with the asperities by Wald and Somerville (1995).

Teleseismic data recorded in USA, Europe, and Australia were collected by Kanamori (1971) and digitized by Wald and Somerville (1995). Figure 3(a) shows the location and azimuthal coverage of the teleseismic stations where useful records were observed. The records were bandpass-filtered between 0.02 and $0.4 \mathrm{~Hz}$, and resampled at a rate of $1.0 \mathrm{~Hz}$. The instrumental responses were deconvolved and a common instrumental response convolved in as was done by Wald and Somerville (1995). We will convolve the Green's functions with the common response in our procedure of a joint inversion.

Strong motion data recorded at observatories of the Japan Meteorological Agency (JMA) and Tohoku Imperial Uni- 
versity (predecessor of the present Tohoku University) at Sendai were collected by Takemura and his colleagues (Takemura, 1994; Takemura et al., 1994, 1995; Takemura and Nozawa, 1996a, b, 1998). They are available on the web site (Kajima Corporation, 2003). We chose the data observed by the Imamura-type strong motion seismo-

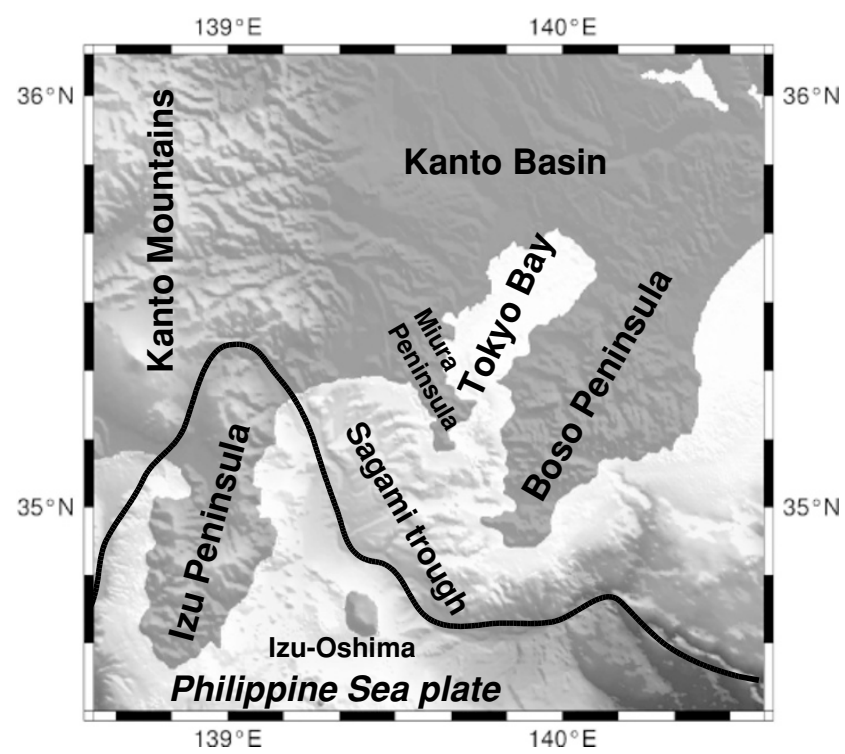

Fig. 1. Geographical setting around the source region of the 1923 Kanto earthquake. A thick line denotes a possible plate boundary between the Philippine Sea and continental plates. graphs, whose stations are plotted in Fig. 3(b). The data are bandpass-filtered between 0.05 and $0.5 \mathrm{~Hz}$ and resampled at a rate of $2 \mathrm{~Hz}$. The instrumental responses were also investigated by Takemura and his colleagues, but we do not deconvolve the instrumental response from the data, so that we will calculate their Green's functions including the response. Note that the later part of the NS component at the Gifu station was clipped off.

In the Tokyo Imperial University (predecessor of the University of Tokyo) at Hongo, Tokyo, the strong motion data were recorded by Omori-, Imamura-, and Ewing-type seismographs. The Ewing seismogram, and the EW component of the Imamura seismogram were restored to ground motions by Morioka (1976, 1980) and Yokota et al. (1989), respectively. However, these restored seismograms have significant differences. The previous study of forward modeling (Sato et al., 1999) showed that the Ewing seismogram, which is dominated by long-period oscillations with a period of $13 \mathrm{~s}$, cannot be explained by the strong motion simulation. On the other hand, the Imamura seismogram is consistent with the simulation results, so we use only the Imamura seismogram for the Hongo station.

Since Yokota et al. (1989) also found the accurate direction of the $\mathrm{EW}$ component to be $\mathrm{E} 13^{\circ} \mathrm{N}$, we will calculate the Green's function in this direction. In addition, Yokota et al. (1989) showed that the seismogram was adequately restored but its amplitude could be underestimated by $15 \%$, and so we scale it up by $15 \%$ for the inversion.

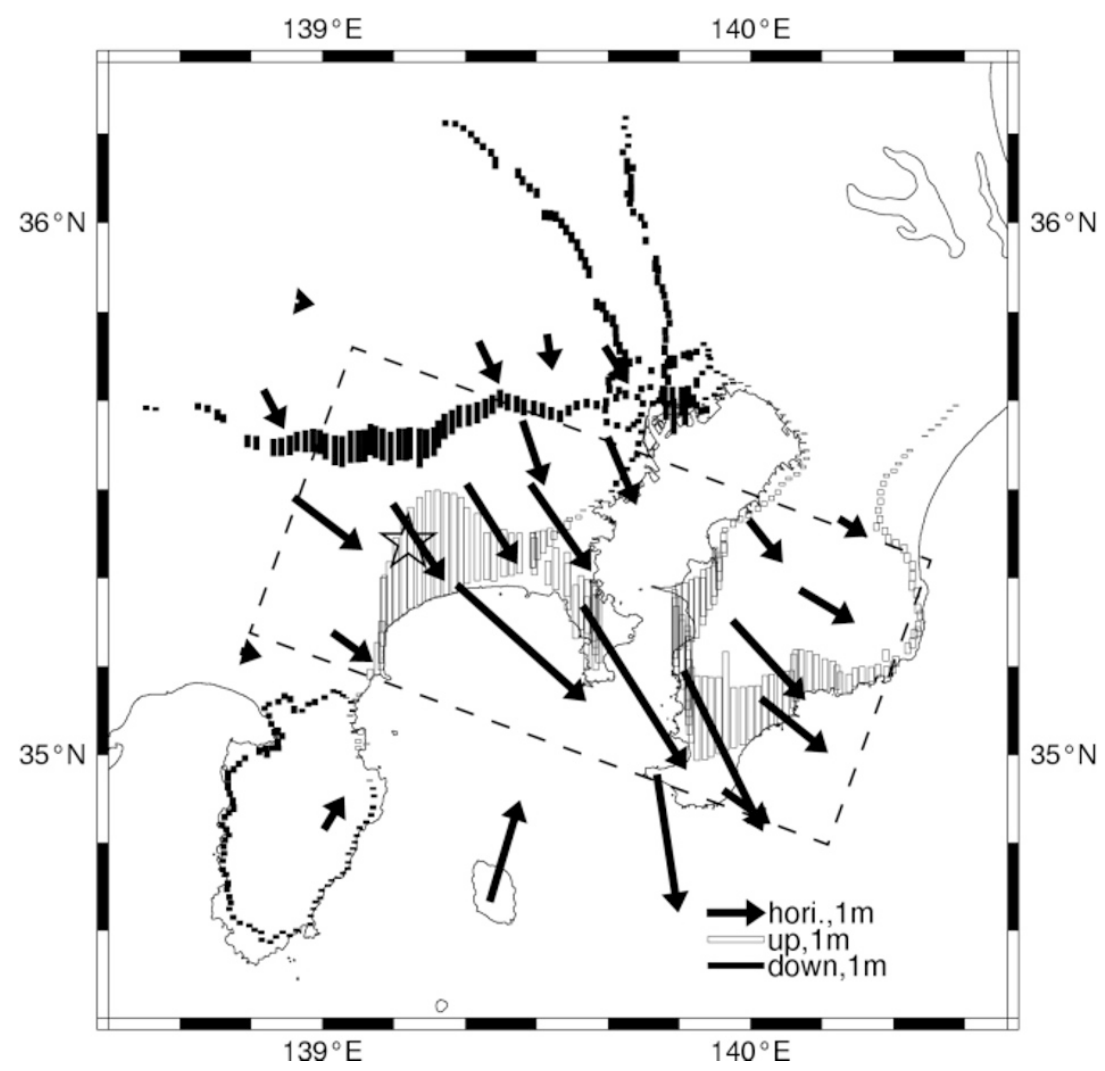

Fig. 2. Observed geodetic data. The arrows denote horizontal displacements from triangulation. The bars denote vertical displacements from leveling (up: white, down: black). The rectangular area bounded by dashed lines indicates the horizontal projection of the fault plane. The star symbol denotes the epicenter. 
(a)

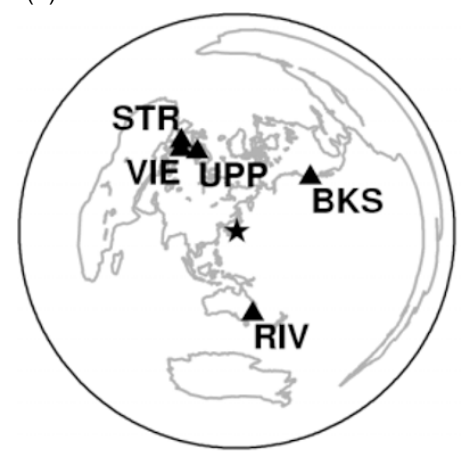

(b)

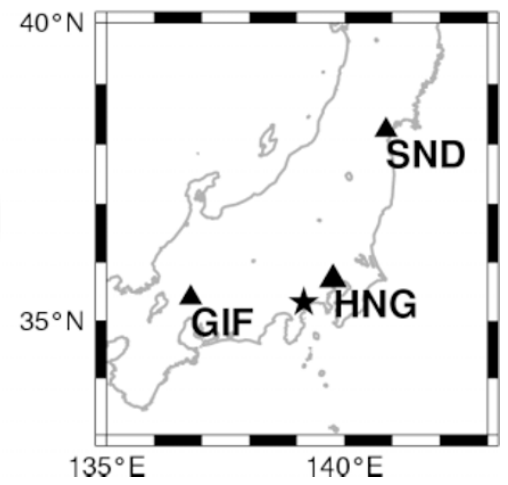

Fig. 3. Distribution of the seismic stations where the data used in this study were observed. (a) Teleseismic stations (UPP: Uppsala, VIE: Vienna, STR: Strasbourg, BKS: Berkeley, RIV: Riverview), and (b) strong motion stations (SND: Sendai, HNG: Hongo, GIF: Gifu).

\section{Method}

For the fault geometry we adopt the model of Wald and Somerville (1995), which was constructed based on Kanamori (1971) and Matsu'ura et al. (1980). The fault parameters of the model are listed in Table 1. The length in the strike direction is $130 \mathrm{~km}$, and the width in the dip direction is $70 \mathrm{~km}$. We divided the fault into seventy $13 \times 10 \mathrm{~km}$ subfaults and made the slip direction at each subfault variable using a combination of $90^{\circ}$ and $180^{\circ}$ slips.

The Green's functions for the geodetic data were calculated by the method of Yabuki and Matsu'ura (1992) in a halfspace medium with a Poisson's ratio of $1 / 4$. We assume that the halfspace medium has a rigidity of $30 \mathrm{GPa}$ when we estimate seismic moments. The Green's functions for the teleseismic data were calculated by a ray theory with the isotropic PREM and the attenuation time constants $\left(t^{*}\right)$ of $1 \mathrm{~s}$ (for $P$-waves) and $4 \mathrm{~s}$ (for $S H$-waves). For strong motion data we used the reflectivity method of Kohketsu (1985) with the 1-D layered structures of Sato et al. (1998a).

We then apply the joint inversion method developed by Yoshida and Koketsu (1990) and Yoshida et al. (1996) to the geodetic, teleseismic and strong motion data. The $k$-th component of the waveforms $F_{k}$ at station $\boldsymbol{x}_{j}$ and at time $t_{i}$ is represented by

$$
\begin{aligned}
F_{k}\left(t_{i}, \boldsymbol{x}_{j}\right)= & \sum_{m n l} X_{m n l} f_{m n k}\left(t_{i}-(l-1) \tau-T_{m n}, \boldsymbol{x}_{j}\right) \\
& +\sum_{m n l} Y_{m n l} g_{m n k}\left(t_{i}-(l-1) \tau-T_{m n}, \boldsymbol{x}_{j}\right),
\end{aligned}
$$

where $f_{m n k}$ and $g_{m n k}$ are the $k$-th components of the seismic Green's functions for the $m n$-th subfault with unit slip in the directions of $90^{\circ}$ and $180^{\circ}$, respectively. $X_{m n l}$ and $Y_{m n l}$ are the slip components in the $m n$-th subfault. The rupture front reaches the $m n$-th subfault at $T_{m n}$. The source time function of a point source is composed of sequential ramp functions with a rise time $\tau$, so that the $l$-th ramp function arises at $T_{m n}+(l-1) \tau$. The $k$-th component of the static displacement $U_{k}$ at station $\boldsymbol{x}_{j}$ is independent of time, and so it is represented by

$$
\begin{aligned}
U_{k}\left(\boldsymbol{x}_{j}\right)= & \sum_{m n}\left(\sum_{l} X_{m n l}\right) u_{m n k}\left(\boldsymbol{x}_{j}\right) \\
& +\sum_{m n}\left(\sum_{l} Y_{m n l}\right) v_{m n k}\left(\boldsymbol{x}_{j}\right),
\end{aligned}
$$

Table 1. Source parameters.

\begin{tabular}{cc}
\hline Origin Time & $1923 / 09 / 0102: 58: 32$ \\
Epicenter & $35.4^{\circ} \mathrm{N}, 139.2^{\circ} \mathrm{E}$ \\
Hypocentral depth & $14.6 \mathrm{~km}$ \\
(Strike, Dip, Rake) & $\left(290^{\circ}, 25^{\circ}, 90-180^{\circ}\right)$ \\
Fault length & $130 \mathrm{~km}$ \\
Fault width & $70 \mathrm{~km}$ \\
Depth of top edge & $2 \mathrm{~km}$ \\
Number of subfaults & $10 \times 7$ \\
\hline
\end{tabular}

where $u_{m n k}$ and $v_{m n k}$ are the $k$-th components of the geodetic Green's functions for the $m n$-th subfault with unit slip in the directions of $90^{\circ}$ and $180^{\circ}$, respectively. For the calculation of $u_{m n k}$ and $v_{m n k}$, we distributed $8 \times 8$ virtual sources and average their displacements for the central point source on each subfault.

We incorporate the positivity and smoothing constrains into the inversion for suppressing numerical instability. The positivity constraint is realized by the penalty functions $1 / \sqrt{X_{m n l}}$ and $1 / \sqrt{Y_{m n l}}$, which can grow rapidly if $X_{m n l}$ and $Y_{m n l}$ approach to zero. The discrete Laplacian operator defined as

$$
\begin{aligned}
\nabla^{2} X_{m n l}= & X_{m+1, n, l}+X_{m, n+1, l}+X_{m, n, l+1} \\
& +X_{m-1, n, l}+X_{m, n-1, l}+X_{m, n, l-1} \\
& -6 X_{m, n, l}
\end{aligned}
$$

is introduced for the smoothing constraint. We determine the relative weights of the geodetic and seismic datasets and the constraints in the inversion following Wald and Somerville (1995) with some considerations mentioned later.

\section{Inversion Results}

\subsection{Inversion of geodetic data alone}

We first inverted the geodetic data alone. Figure 4 shows the resultant slip distribution and compares the observed and calculated displacements. This solution indicates two asperities, one near the hypocenter around the base of the 
(a)

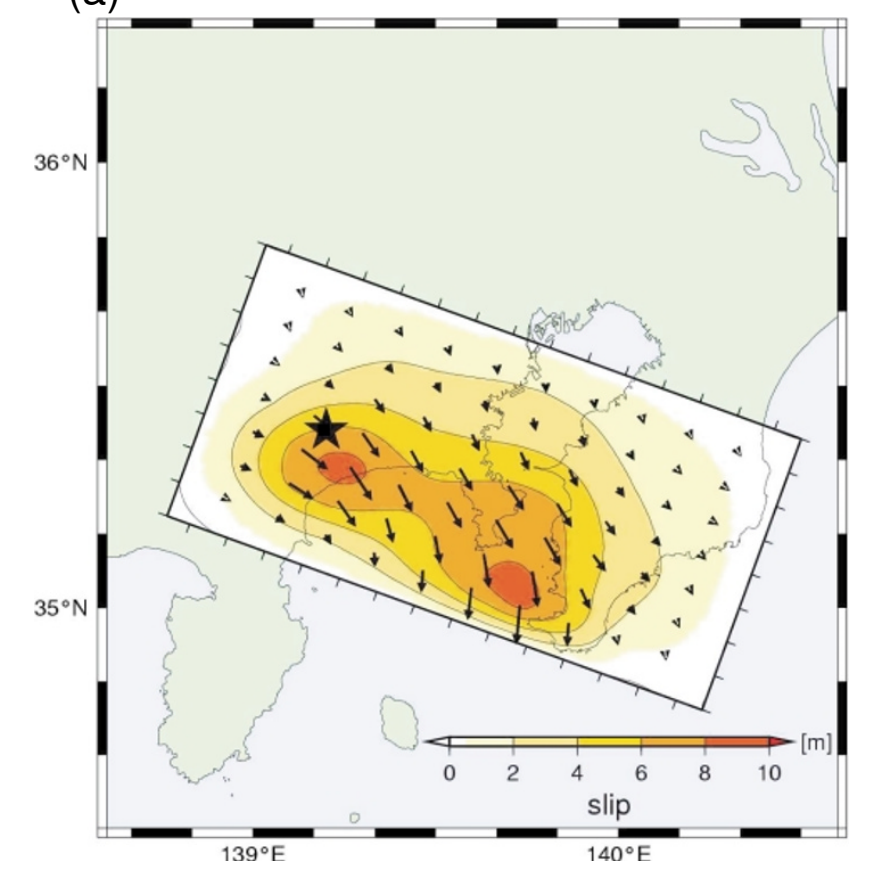

(b)

(c)

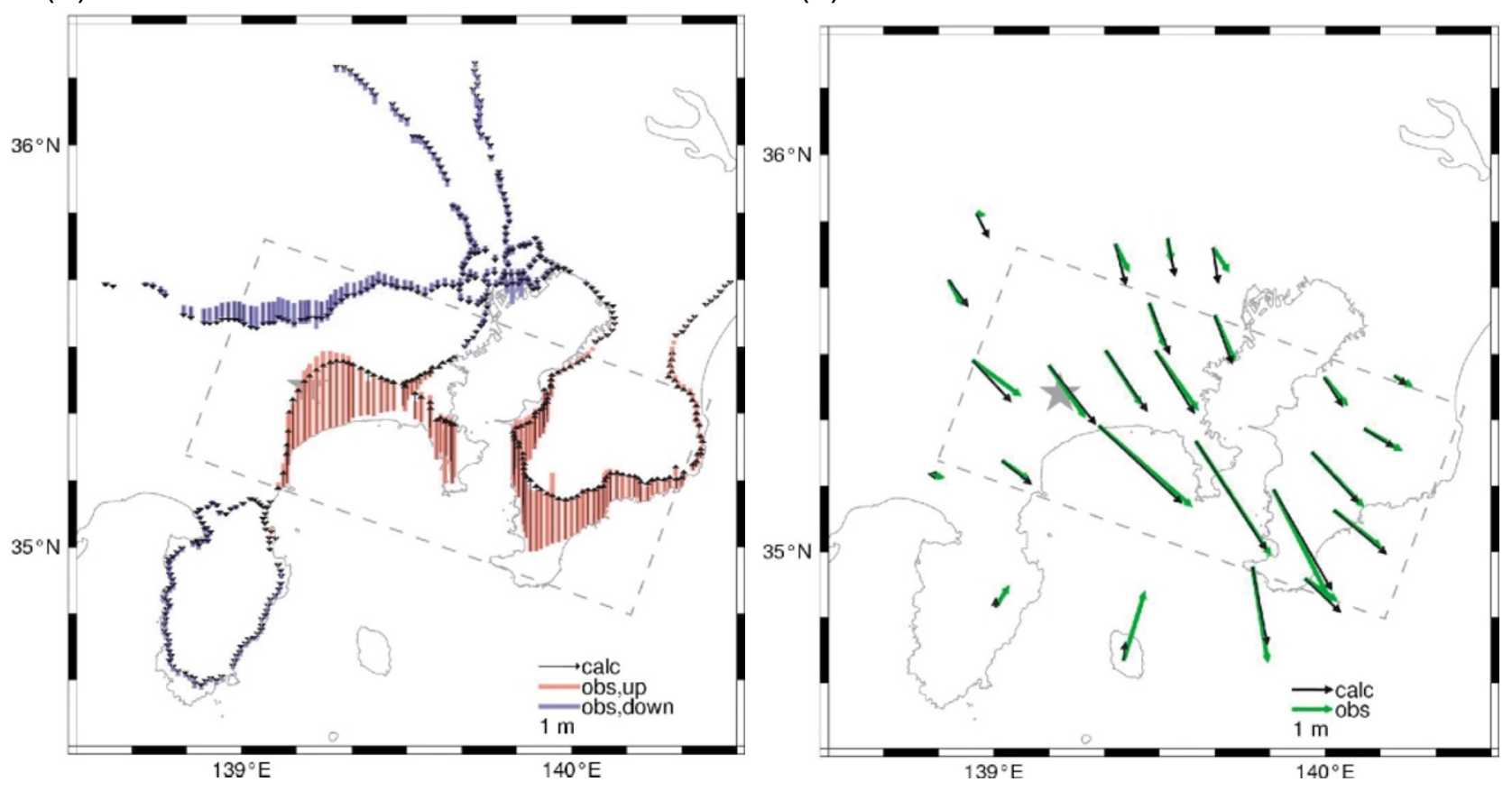

Fig. 4. Result from a inversion of the geodetic data alone. (a) Slip distribution. (b) Observed (up: red, down: blue) and calculated (black) vertical displacements. (c) Observed (green) and calculated (black) horizontal displacements. The variance reduction for geodetic data is 0.96.

Izu Peninsula and another on the shallow, eastern part of the fault plane around the Uraga Strait between the Miura and Boso Peninsulas. Their maximum slips are $8.6 \mathrm{~m}$ and $8.5 \mathrm{~m}$, respectively. The slip direction changes from predominantly right-lateral strike slip around the hypocentral region to near dip slip in the eastern asperity. These features of the slip distribution are consistent with the result of Wald and Somerville (1995). The calculated displacements are in good agreement with the observed ones as shown in Fig. 4. The two peaks of uplifts have been inverted into the asperities mentioned above. The small descents in the
Kanto Basin and along the northern coast of the Tokyo Bay constrain the extents of the asperities.

We note significant discrepancies between the observed and calculated horizontal displacements at the Izu-Oshima station. They cannot be reduced, even if we apply a heavier weight to this $1.8 \mathrm{~m}$ displacement during the inversion. Since only this station and another in the Izu Peninsula are located on the Philippine Sea plate and the postseismic survey was carried out about 25 years after the preseismic one, it is plausible that the discrepancies may be caused by the plate motion. However, the relative motion of the Philippine 
(a)

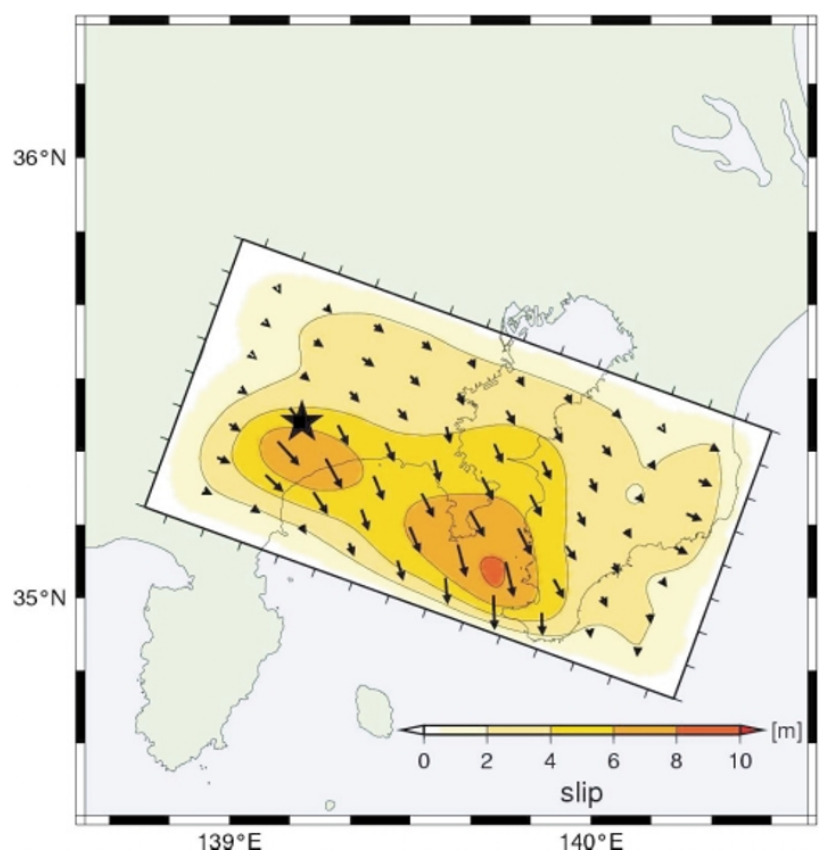

(d)

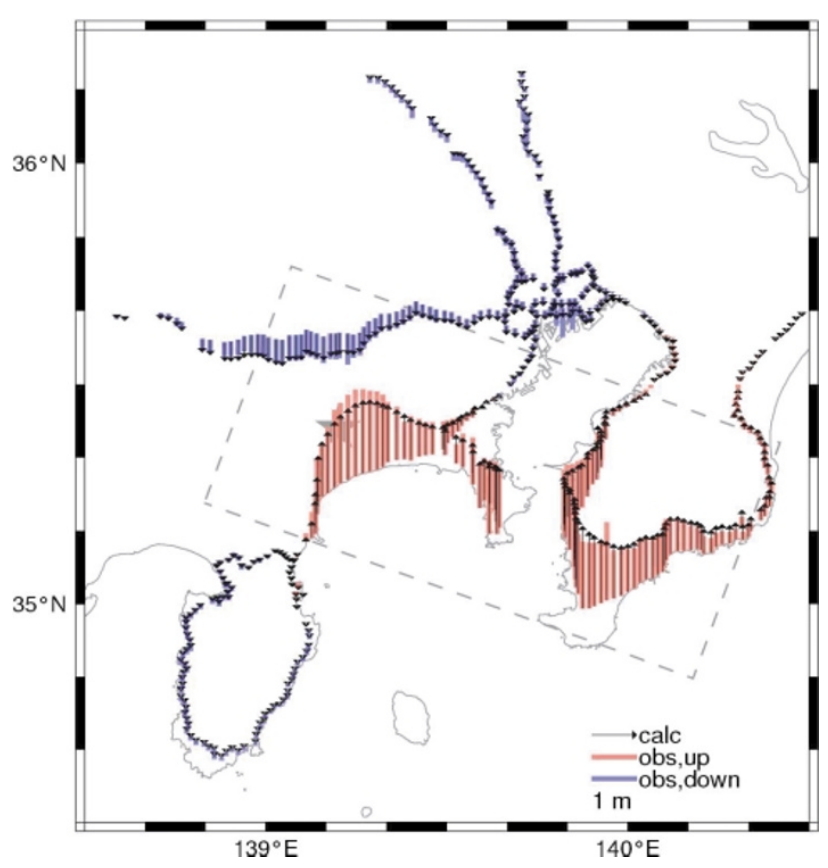

(b)

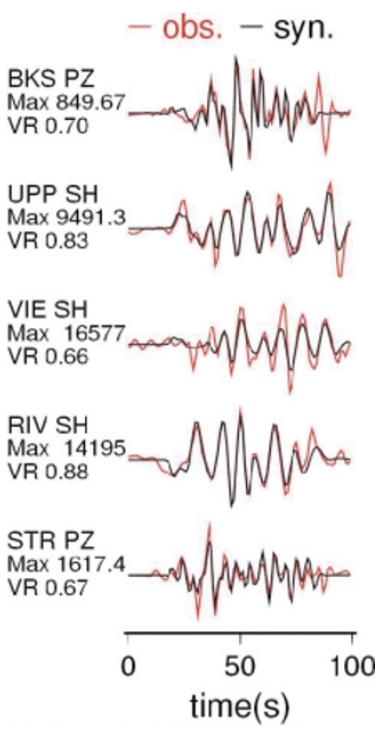

(c)

(e)
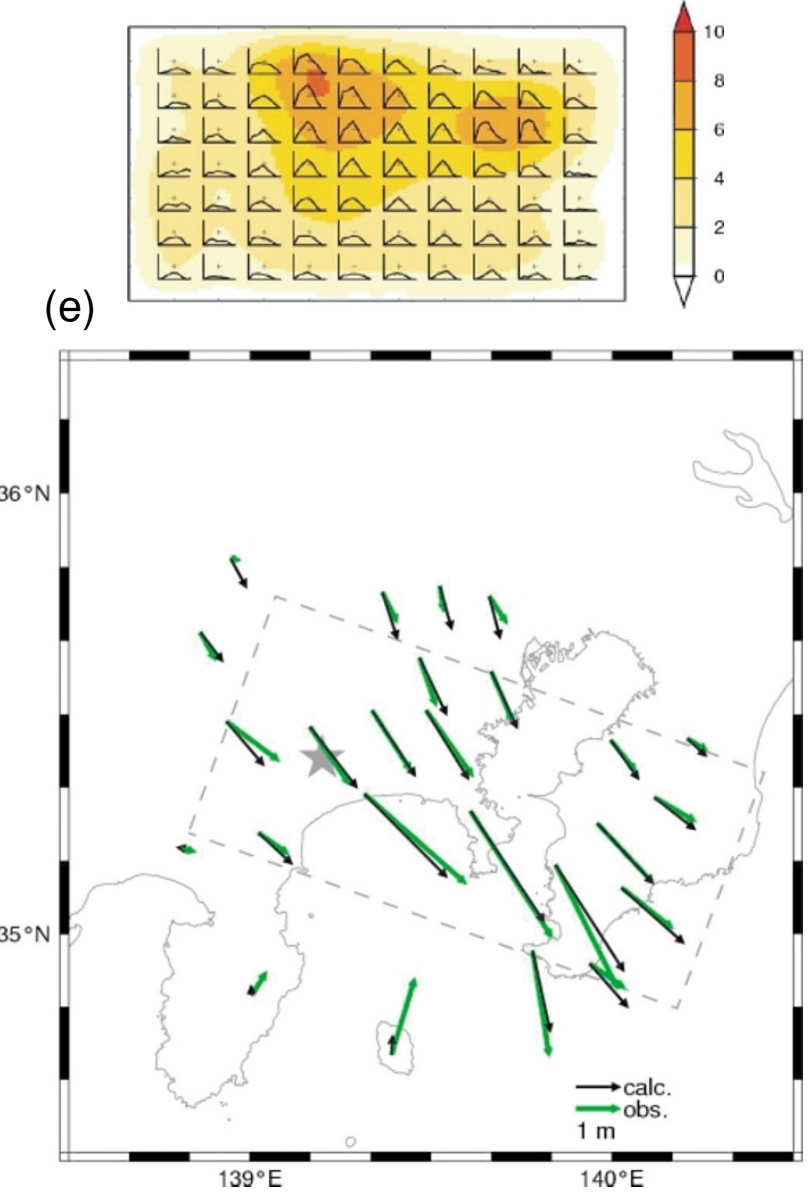

Fig. 5. Result from a inversion of the geodetic and teleseismic data. (a) Slip distribution. (b) Observed (red) and calculated (black) waveforms. Maximum amplitude (Max) in $\mu \mathrm{m}$ and variance reduction (VR) are given to the left of each waveform. (c) Slip rate function at each subfault. The crosses denote the locations of the point sources in the subfaults. (d) Observed (up: red, down: blue) and calculated (black) vertical displacements. (e) Observed (green) and calculated (black) horizontal displacements. The variance reduction for geodetic data is 0.95 .

Sea plate to the continental plate is $2-3 \mathrm{~cm} / \mathrm{yr}$ to the northwest (Sagiya, 1999; Heki and Miyazaki, 2001), so that the total movement during the period amounts to $50-75 \mathrm{~cm}$, which is only a third of the observed horizontal displacement. We have to find other causes for the remaining two thirds. Izu-Oshima is a volcanic island, which erupted in 1910 (volume of erupted solid material $1 \times 10^{5} \mathrm{~m}^{3}$ ), 1912- $1914\left(3.3 \times 10^{7} \mathrm{~m}^{3}\right)$, and $1921-1922\left(1 \times 10^{5} \mathrm{~m}^{3}\right)$, according to Nakamura (1964). These volcanic activities may have resulted in these two thirds.

\subsection{Joint inversions}

We next inverted the geodetic and teleseismic data simultaneously (Fig. 5). The temporal feature of the source process was introduced by the source time function consisting 
(a)

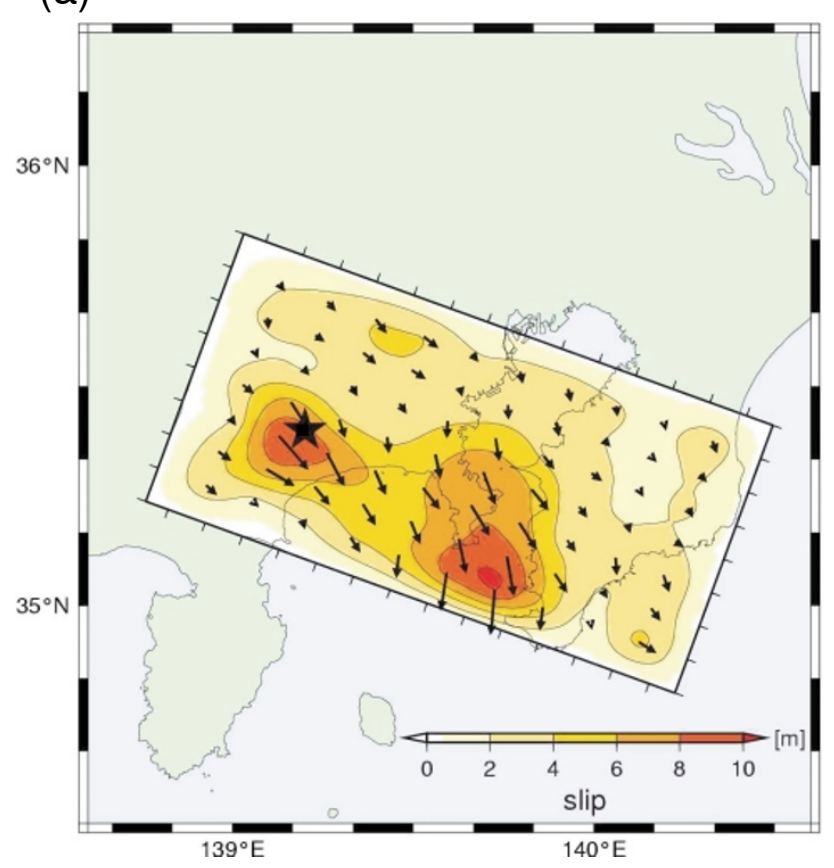

(b)

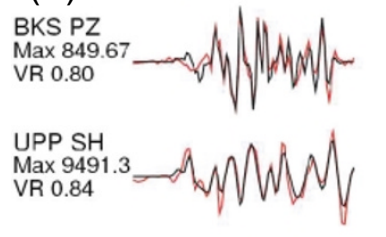

VIE SH

$\operatorname{Max} 1657$
VR 0.62

RIV SH

$\operatorname{Max} 1419$

VR 0.83

STR PZ
Max 1617
VR 0.70

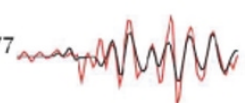

SND NS

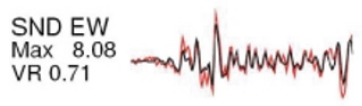

V

(c)

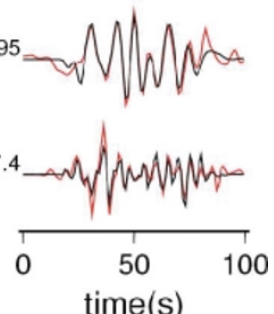

Max 7.28 reaph nelly

- obs. - syn.

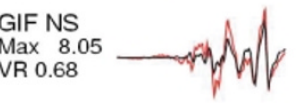

GIF EW
Max 7.27 MR 0.73
VRomply

Max 29.5

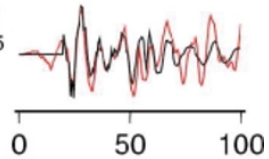

c)

(e)

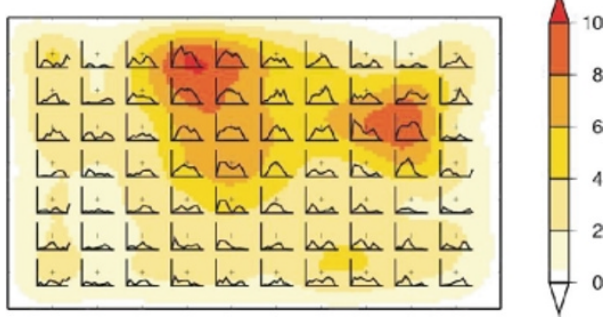

(d)

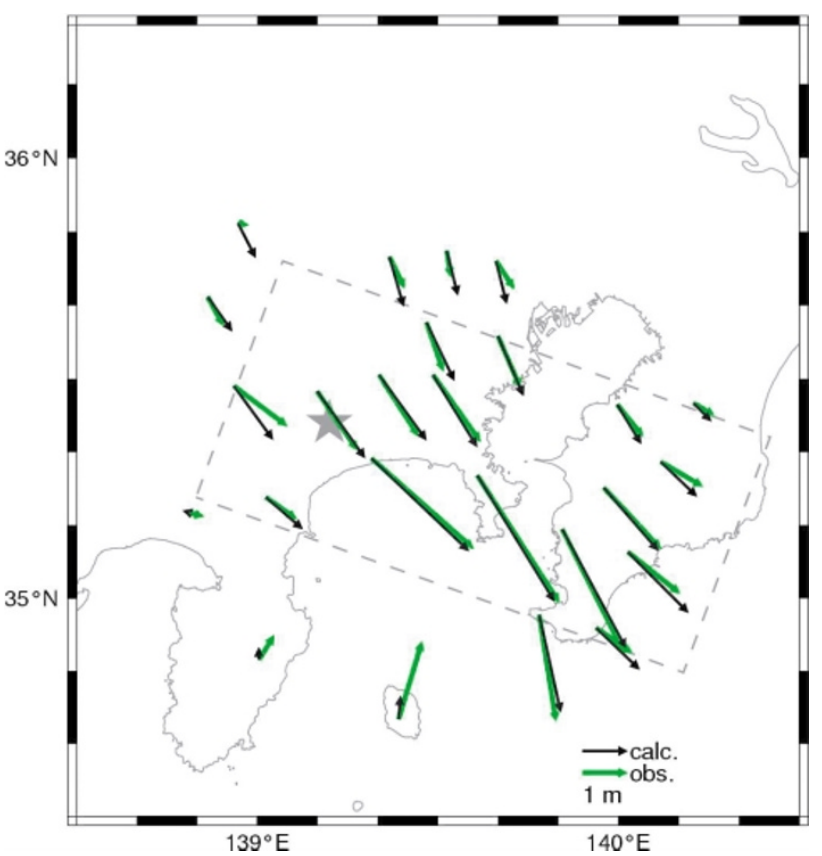

Fig. 6. Result from a inversion of the geodetic, teleseismic and strong motion data. (a) Slip distribution. (b) Observed (red) and calculated (black) waveforms. Maximum amplitude (Max) in $\mu \mathrm{m}$ (for teleseismic data, left) or in $\mathrm{cm}$ (for strong motion data, right) and variance reduction (VR) are given to the left of each waveform. (c) Slip rate function at each subfault. (d) Observed (up: red, down: blue) and calculated (black) vertical displacements. (e) Observed (green) and calculated (black) horizontal displacements. The variance reduction for geodetic data is 0.95 .

of seven ramp functions with a rise time of $1.5 \mathrm{~s}$. We carried out the inversion with the rupture front velocities between 2.5 and $4.0 \mathrm{~km} / \mathrm{s}$, and chose a velocity of $2.6 \mathrm{~km} / \mathrm{s}$ which minimizes the variance.

Since we cannot expect exact information on timing and instrumental responses of historical seismograms, we chose a heavier weight for the geodetic data than that for the seis- mograms to obtain a stable solution. In spite of this lower weight, the seismograms are well recovered as shown in Fig. 5(b). The resultant slip distribution in Fig. 5(a) is mostly similar to that of the geodetic inversion, though the western asperity near the hypocenter is somewhat weakened. The eastern asperity with a maximum slip of $9.2 \mathrm{~m}$ becomes larger than the western one, and the total seismic 


\section{(a) Geodetic + Teleseismic + Strong Motion}
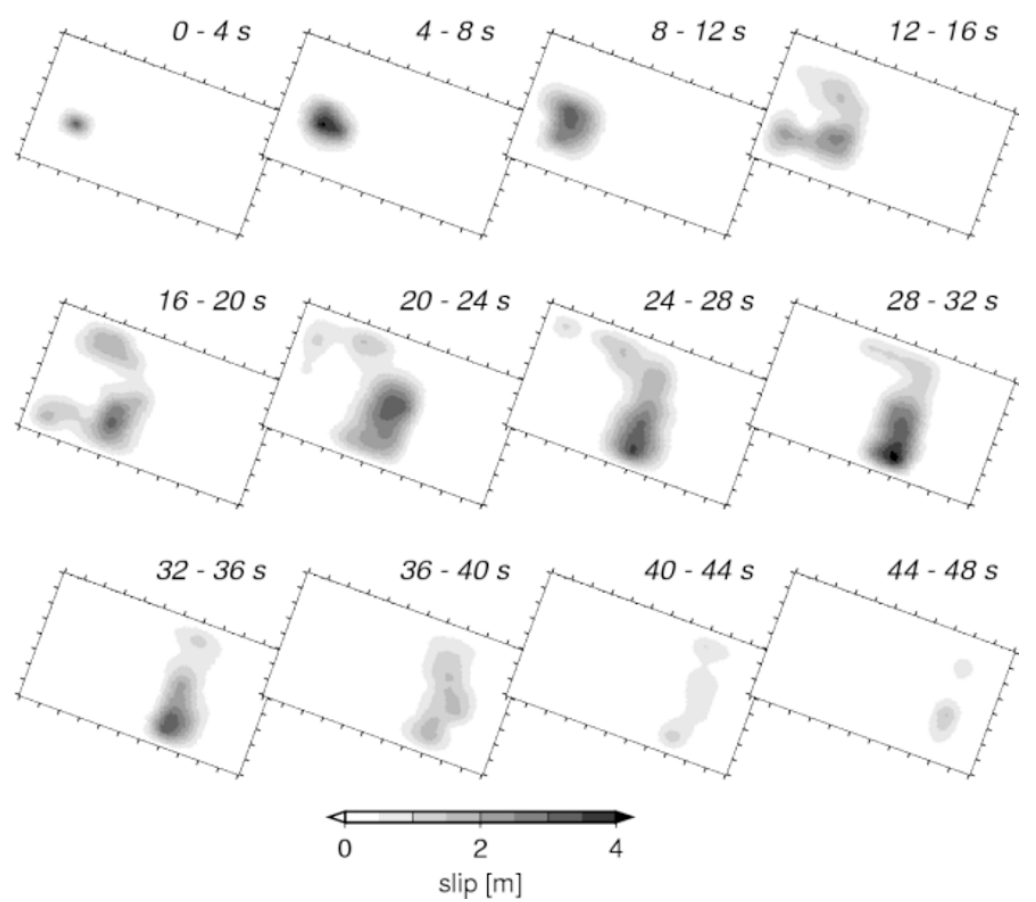

(b) Geodetic + Teleseismic
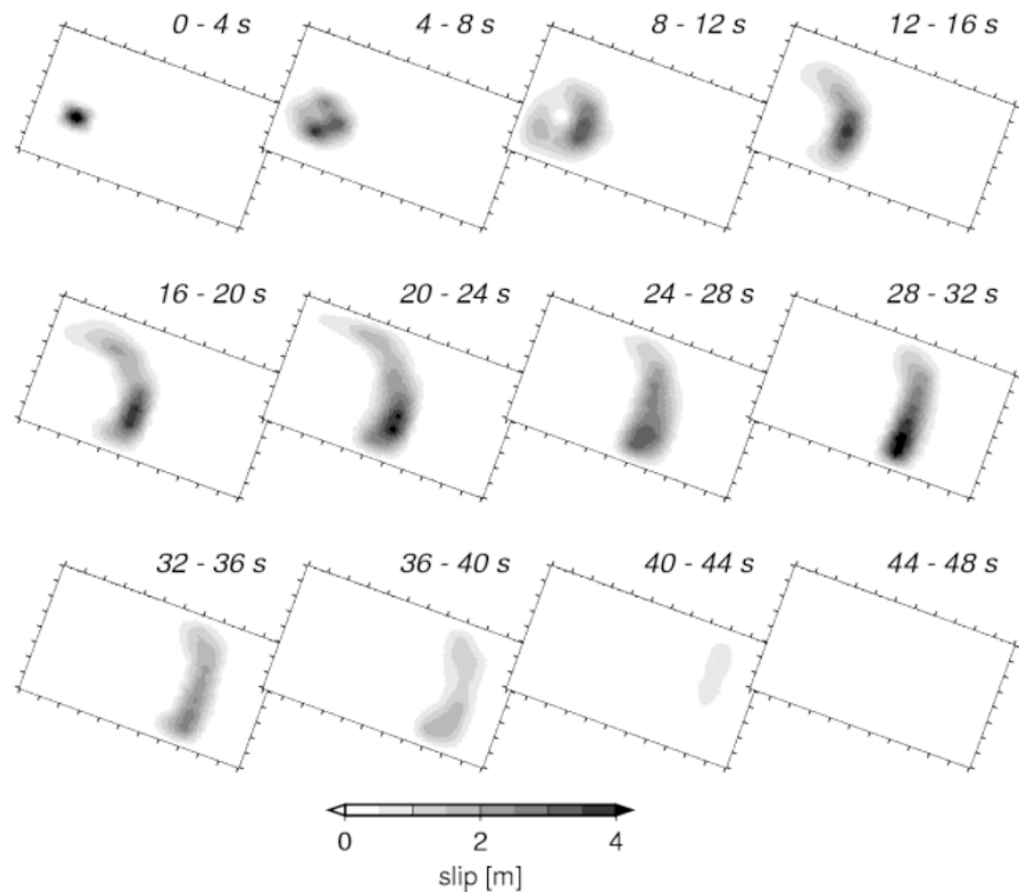

Fig. 7. Slip distribution during each of the $4 \mathrm{~s}$ time window (a) from the three-fold joint inversion with the strong motion data and (b) from the two-fold joint inversion without the strong motion data.

moment is $1.0 \times 11^{21} \mathrm{Nm}\left(\mathrm{M}_{w} 7.9\right)$. The slip velocity functions in Fig. 5(c) indicate that the seismic moment in the first (western) asperity was released more rapidly than those in the second (eastern) asperity. This feature was also found by Wald and Somerville (1995).

We finally inverted the geodetic, teleseismic and strong motion data all together (Fig. 6). In this case, we increased the number of ramp functions from seven to ten, because a preliminary inversion with seven functions showed that slips in the eastern asperity were still large at the seventh function. The best rupture front velocity was not changed after the strong motion dataset were added.

Compared with the results of the two-fold joint inversion without the strong motion dataset or the results of Wald and Somerville (1995), the asperities have been intensified and the area of the eastern asperity has been expanded to 
(a)

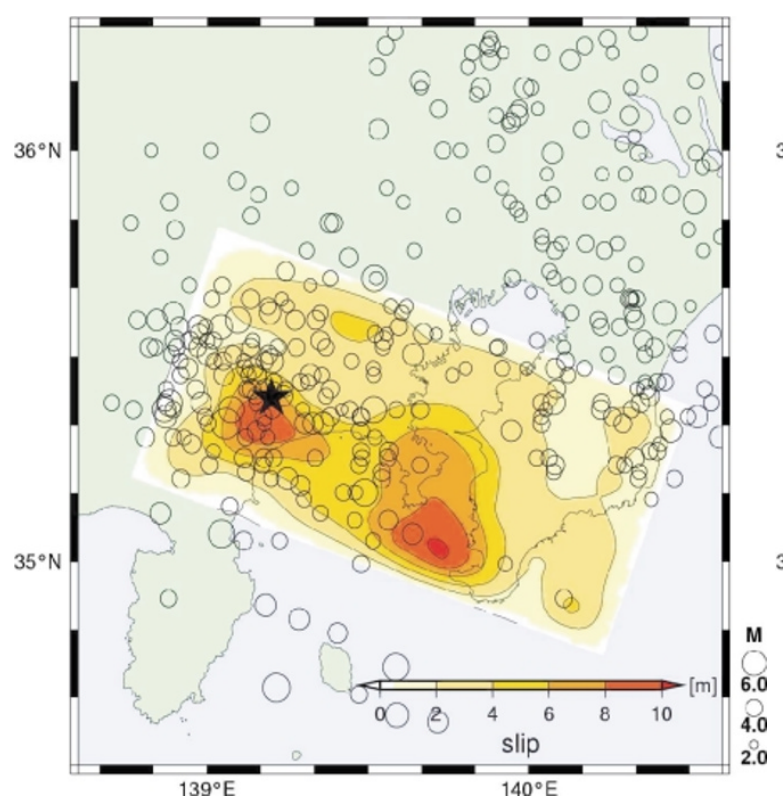

(b)

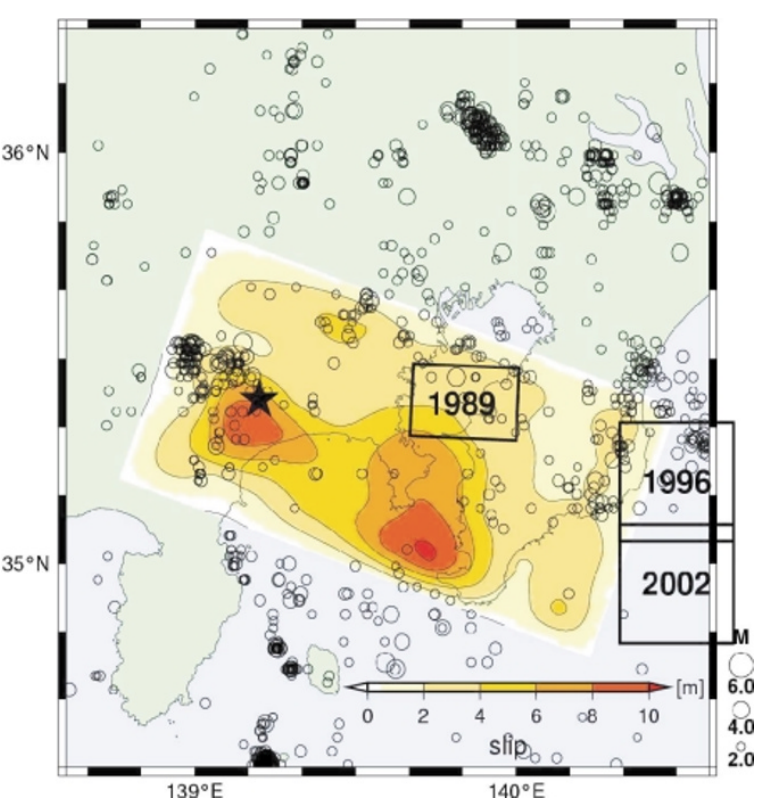

Fig. 8. Seismicity and slip distribution. (a) Aftershock distribution in three years after the main shock. (b) Seismicity during 1999-2003. We plot the events shallower than $50 \mathrm{~km}$ with larger magnitudes than 2.0. The source regions of the 1989, 1996, and 2002 silent earthquakes (aseismic slip events) are also displayed with black rectangles.

the north in this final model of the slip distribution. The maximum slip and total moment increase from $9.2 \mathrm{~m}$ and $1.0 \times 10^{21} \mathrm{Nm}\left(\mathrm{M}_{w} 7.9\right)$ to $10.0 \mathrm{~m}$ and $1.1 \times 10^{21} \mathrm{Nm}$ $\left(\mathrm{M}_{w}\right.$ 8.0), respectively. In other words, the larger slips are required for recovering the amplitudes of the strong motions. The synthetic teleseismic waveforms keep good agreement with the observed ones.

In the resultant slip velocity functions (Fig. 6(c)), the above feature (abrupt rise of the moment release in the first asperity, and gradual rise in the second one) appears less distinct than in those from the geodetic and teleseismic data. However, we can still say that the initial rises in the first asperity are more rapid than those in the second one.

Although most of the seismic data are well recovered, the coda part of the synthetic seismogram at Hongo is not in good agreement with the observed one. The large coda wave train cannot be reproduced by using a 1-D structure, even if the structure contains soft, thick sediments (e.g., Sato et al., 1998b). Forward modeling with a 3-D structure (Sato et al., 1999) showed that surface waves excited along the boundary between the Kanto Mountains and Kanto Basin (Fig. 1) can explain the large coda at Hongo.

Figure 7 represents the growth of the rupture by showing the slip-rate distributions every $4 \mathrm{~s}$. If we compare the distribution from the three-fold joint inversion with the strong motion dataset with the one from the two-fold joint inversion without the strong motion dataset, we can find details of the source process in the former including the shorterlength features. This implies that the strong motion data provided us with much more information on the source time function than the teleseismic data, and we inferred a clearer image of the rupture process from them.

\section{Discussion}

Hamada et al. (2001) precisely relocated the hypocenters of aftershocks of the 1923 Kanto earthquake. Figure 8(a) shows the epicenters of the aftershocks with horizontal errors less than $10 \mathrm{~km}$ in three years after the main shock. The comparison between the aftershock and the present slip distributions suggests few aftershocks around the larger eastern asperity as expected from the established theory on aftershock patterns and main shock faulting (e.g., Mendoza and Harzell, 1988). However, many small aftershocks occurred in and around the western asperity. A possible reason for this contradiction may be that the rupture in the western asperity was not completed during the main shock. Ito et al. (2004) and Yagi (2004) found that the aftershocks of the 2003 Tokachi-oki earthquake did not occur on the surface of the Pacific slab in the asperity regions, but within the plates above and below the asperity regions. Thus it might also be possible that the aftershocks in the western asperity of the 1923 Kanto earthquake were intraplate events, but we cannot show any evidence because the focal depths of the aftershocks were not well determined. Figure 8(b) represents the recent seismicity in 2000-2003, showing events shallower than $50 \mathrm{~km}$ with magnitudes larger than 2.0. We still find null seismicity in the eastern asperity. The seismicity in the western asperity becomes lower, suggesting that the coupling between the slab and continental plate is getting recovered there.

Silent earthquakes (aseismic slip events) have recently been detected thanks to the development of the continuous crustal tilts observation and Global Positioning System (GPS) network. In the Kanto region, Hirose et al. (2000), Ozawa et al. (2003), and Sagiya (2004) found such events in 1989, 1996, and 2002. Their source regions are located in the middle part of the Tokyo Bay or in the east of the 


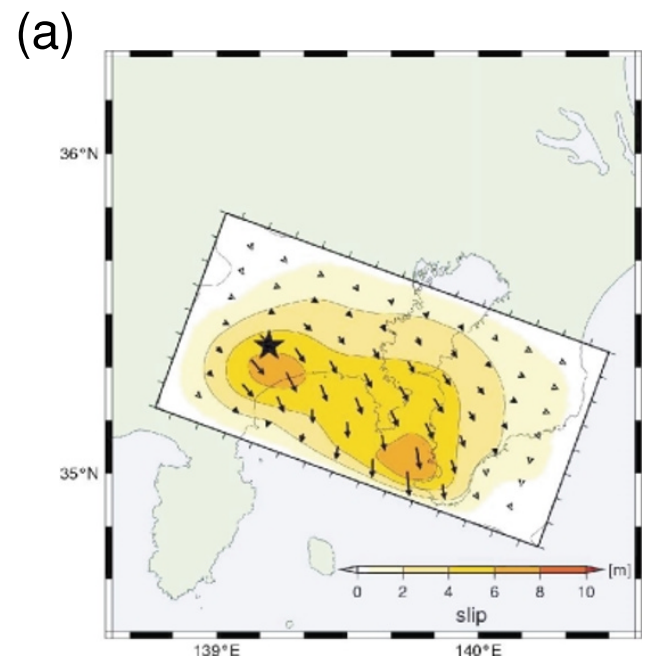

(b)

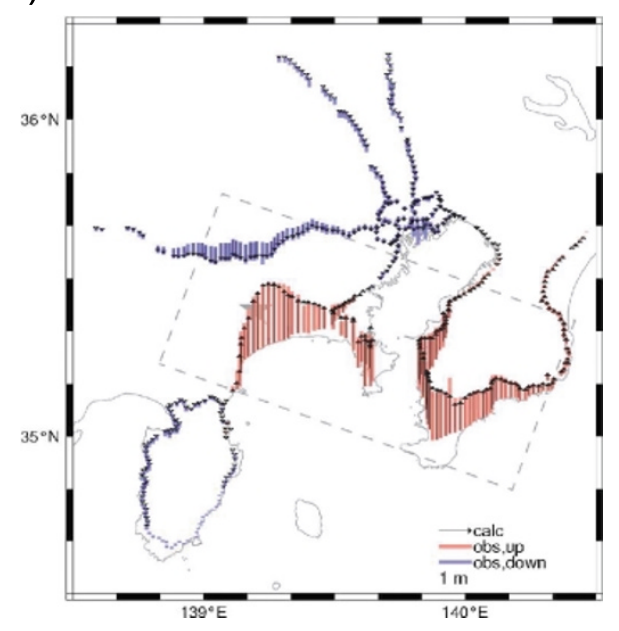

(c)

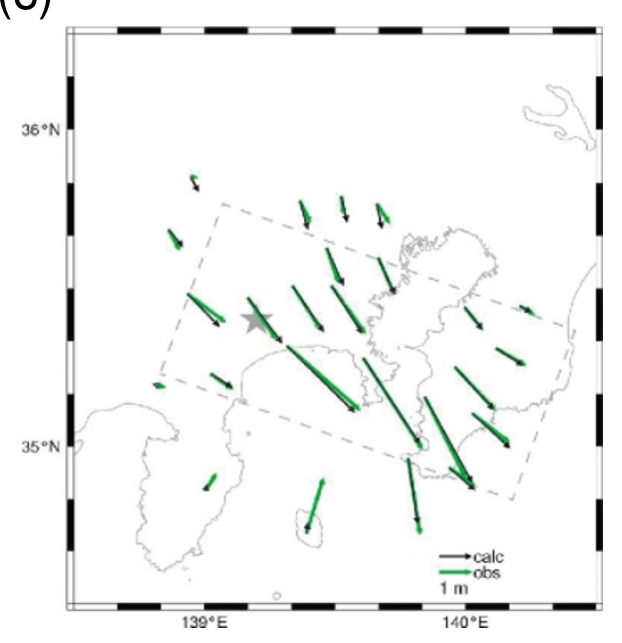

Fig. 9. Results from inversions of the geodetic data using the Green's functions for a 1-D layered structure. (a) Slip distribution. (b) Observed (up: red, down: blue) and calculated (black) vertical displacements. (c) Observed (green) and calculated (black) horizontal displacements. The variance reduction for geodetic data is 0.96 .

Boso Peninsula neighboring the eastern asperity as shown in Fig. 8(b). Similar silent earthquakes adjacent to asperities of large earthquakes have also been found in other regions (Yagi and Kikuchi, 2003), and so it may imply an important process during earthquake cycles.

We assessed the effect of Green's functions calculated for a 1-D layered structure on the inversion of geodetic data alone. We used the same structure model as that used for the strong motion data at Hongo (Sato et al., 1998a). The frequency-wavenumber method of Zhu and Rivera (2002) is used to calculate the Green's functions for the geodetic data. Figure 9 shows the result with the 1-D Green's functions. The soft sedimentary layer in the 1-D structure increases the displacements, so that the 1-D Green's functions reduced the slip amounts. The maximum slips in the western and eastern asperities decreased from $8.6 \mathrm{~m}$ and $8.5 \mathrm{~m}$ to $6.9 \mathrm{~m}$ and $7.5 \mathrm{~m}$, respectively. The total seismic moment, however, increased from $9.2 \times 10^{20} \mathrm{Nm}$ to $9.7 \times 10^{20} \mathrm{Nm}$, because the rigidities at depths of $12-34 \mathrm{~km}$ are $39-46 \mathrm{GPa}$, which are higher than that of $30 \mathrm{GPa}$ for the halfspace model (the rigidity at depths of $3-12 \mathrm{~km}$ is $29 \mathrm{GPa}$, which differs little from that for the halfspace model). The vari- ance reduction was not changed. These effects may be applicable to the results of the joint inversions. We used a 1-D model in this assessment, the real structure in the Kanto region should be three-dimensionally complex as suggested by the geographical setting in Fig. 1. The Green's functions for this 3-D structure are necessary in the next stage of our study.

\section{Conclusion}

We carried out a joint inversion of geodetic, teleseismic and strong motion data for the source process of the 1923 Kanto earthquake. There are two asperities (areas of large slips) in the resultant slip distribution. The new strong motion data improved the resolution, so that the asperities were intensified with longer rupture duration and the eastern asperity was recovered with a larger area than in the result of the two-fold joint inversion of the geodetic and teleseismic data or the result of Wald and Somerville (1995). The maximum slip is $10.0 \mathrm{~m}$ and the total seismic moment is $1.1 \times 10^{21} \mathrm{Nm}\left(\mathrm{M}_{w} 8.0\right)$, while the two-fold joint inversion recovered the maximum slip of $9.2 \mathrm{~m}$ and the moment of $1.0 \times 10^{21} \mathrm{Nm}\left(\mathrm{M}_{w} 7.9\right)$. The recovered slip functions 
indicate that the initial rise was abrupt in the western asperity, while it was gradual in the eastern asperity. There are very few aftershocks in the eastern asperities, though many small aftershocks occurred in and around the western asperity. The source regions of the 1989, 1996, and 2002 silent earthquakes are located in the zones neighboring the eastern asperity.

Acknowledgments. This work is carried out as a part of the Special Project for Earthquake Disaster Mitigation in Urban Areas supported by the Ministry of Education, Culture, Sports, Science and Technology of Japan. We thank M. Takemura, S. Kataoka, D. Wald, and Japan Meteorological Agency for providing us with the seismic data. We also thank all the staffs for recording and managing the historical seismic and geodetic data. D. Wald, Y. Yagi, and E. Fukuyama gave us thoughtful comments which greatly improved the manuscript. The figures were drawn by using the Generic Mapping Tools (Wessel and Smith, 1991).

\section{References}

Hamada, N., K. Yoshikawa, M. Nishiwaki, M. Abe, and F. Kusano, A comprehensive study of aftershocks of the 1923 Kanto earthquake, Zisin 2, 54, 251-265, 2001 (in Japanese with English abstract).

Heki, K. and S. Miyazaki, Plate convergence and long-term crustal deformation in central Japan, Geophys. Res. Lett., 28, 2313-2316, 2001.

Hirose, I., I. Kawasaki, Y. Okada, T. Sagiya, and Y. Tamura, A silent earthquake of December 9, 1989, in the Tokyo Bay, as revealed by the continuous observation of crustal movements in the southern Kanto district, central Japan, Zisin 2, 53, 11-23, 2000 (in Japanese with English abstract).

Ito, Y., H. Matsubayashi, H. Kimura, T. Matsumoto, Y. Asano, and S. Sekiguchi, Spatial distribution for moment tensor solutions of the 2003 Tokachi-oki earthquake $\left(\mathrm{M}_{J M A}=8.0\right)$ and aftershocks Earth Planets Space, 56, 301-306, 2004.

Kajima Corporation, Digital strong motion data of the 1923 Kanto earthquake recorded by Imamura-type seismographs, http://www.kajima.co. jp/tech/katri/technical/earthquake1923/, 2003 (in Japanese).

Kanamori, H., Faulting of the great Kanto earthquake of 1923 as revealed by seismological data, Bull. Earthq. Res. Inst., 49, 13-18, 1971.

Kanamori, H. and S. Miyamura, Seismological re-evaluation of the great Kanto earthquake of September 1, 1923, Bull. Earthq. Res. Inst., 48, 115-125, 1970.

Kohketsu, K., The extended reflectivity method for synthetic near-field seismograms, J. Phys. Earth, 33, 121-131, 1985.

Matsu'ura, M. and T. Iwasaki, Study on coseismic and postseismic crustal movements associated with the 1923 Kanto Earthquake, Tectonophysics, 97, 201-215, 1983.

Matsu'ura, M., T. Iwasaki, Y. Suzuki, and R. Sato, Statical and dynamical study on faulting mechanism of the 1923 Kanto earthquake, J. Phys. Earth, 28, 119-143, 1980.

Matsuda, T., Y. Ota, M. Ando, and N. Yonekura, Fault mechanism and recurrence time of major earthquakes in southern Kanto district, Japan, as deduced from coastal terrace data, Geol. Soc. Am. Bull., 89, 1610$1618,1978$.

Mendoza, C. and S. H. Hartzell, Aftershock patterns and main shock faulting, Bull. Seism. Soc. Am., 78, 1438-1449, 1988.

Military Land Survey, Re-survey of the Kwanto district after the great earthquake of 1923, Bull. Imp. Earthq. Invest. Comm., 11, 1-6, 1930.

Morioka, T., Ground motion of the 1923 Kanto earthquake, Proc. 4th Symp. Ground Motions, Architectural Inst. Japan, 38-48, 1976.

Morioka, T., The ground motion of the great Kwanto earthquake of 1923, Trans. Architectural Inst. Japan, 289, 79-88, 1980.

Nakamura, K., Volcano-stratigraphic study of Oshima Volcano, Izu, Bull. Earthq. Res. Inst., 42, 649-728, 1964.

Ozawa, S., S. Miyazaki, Y. Hatanaka, T. Imakiire, M. Kaidzu, and M. Murakami, Characteristic silent earthquake in the eastern part of the Boso peninsula, Central Japan, Geophys. Res. Lett., 30, 1283, doi:10.1029/2002GL016665, 2003.

Sagiya, T., Interplate coupling in the Tokai District, central Japan deduced from continuous GPS data, Geophys. Res. Lett., 26, 2315-2318, 1999.

Sagiya, T., Interplate coupling in the Kanto district, central Japan, and the Boso Peninsula silent earthquake in May 1996, Pure Appl. Geophys.,
161, 2327-2342, 2004.

Sato, H. and M. Ichihara, On the revision triangulation after the great Kanto earthquake, J. Geod. Soc. Japan, 17, 178-186, 1971 (in Japanese with English abstract).

Sato, T., D. V. Helmberger, P. G. Somerville, R. W. Graves, and C. K. Saikia, Estimates of regional and local strong motions during the great 1923 Kanto, Japan, Earthquake (Ms 8.2). Part 1: Source estimation of a calibration event and modeling of wave propagation paths, Bull. Seism. Soc. Am., 88, 183-205, 1998a.

Sato, T., R. W. Graves, P. G. Somerville, and S. Kataoka, Estimates of regional and local strong motions during the great 1923 Kanto, Japan, Earthquake (Ms 8.2). Part 2: Forward simulation of seismograms using variable-slip rupture models and estimation of near-fault long-period ground motions, Bull. Seism. Soc. Am., 88, 206-227, 1998b.

Sato, T., R. W. Graves, and P. G. Somerville, Three-dimensional finitedifference simulation of long-period strong motion in the Tokyo metropolitan area during the 1990 Odawara earthquake (Mj 5.1) and the great 1923 Kanto earthquake (Ms 8.2) in Japan, Bull. Seism. Soc. Am., 89, 579-607, 1999.

Sugimura, A. and Y. Naruse, Changes in sea level, seismic upheavals, and coastal terraces in the southern Kanto region, Japan (I), Japan. J. Geol. Geogr., 14, 101-113, 1954.

Takemura, M., Aftershock activities for two days after the 1923 Kanto earthquake $(\mathrm{M}=7.9)$ inferred from seismograms at Gifu Observatory, Zisin 2, 46, 439-455, 1994 (in Japanese with English abstract).

Takemura, M. and T. Nozawa, Strong motion records from the 1923 Kanto earthquake observed at the Takada observatory, Zisin 2, 49, 91-100, 1996a (in Japanese).

Takemura, M. and T. Nozawa, Strong motion records from the 1923 Kanto earthquake observed at the Yamagata observatory-Instrument and comparison of the records at the Mukaiyama Observatory, Sendai, Zisin 2, 49, 375-387, 1996b (in Japanese with English abstract).

Takemura, M. and T. Nozawa, Strong motion records from the 1923 Kanto earthquake and its aftershocks observed at the Nagasaki and Akita observatories, Zisin 2, 51, 239-251, 1998 (in Japanese with English abstract).

Takemura, M., T. Ikeura, K. Kudo, and H. Ohnuma, Strong motion records from the 1923 Kanto earthquake observed at the Gifu observatory, Zisin 2, 47, 193-200, 1994 (in Japanese).

Takemura, M., K. Kudo, T. Nozawa, T. Sato, and S. Kataoka, Strong motion records from the 1923 Kanto earthquake observed at the Mukaiyama observatory of Tohoku Imperial University at Sendai, Zisin 2, 48, 297-306, 1995 (in Japanese).

Wald, D. J. and P. G. Somerville, Variable-slip rupture model of the great 1923 Kanto, Japan, earthquake: geodetic and body-waveform analysis, Bull. Seism. Soc. Am., 85, 159-177, 1995.

Wessel, P. and W. H. F. Smith, Free software helps map and display data, Eos, Trans., Am. Geophys. Union, 72, 441-446, 1991.

Yabuki, T. and M. Matsu'ura, Geodetic data inversion using a Bayesian information criterion for spatial distribution of fault slip, Geophys. $J$. Int., 109, 363-375, 1992.

Yagi, Y., Source rupture process of the 2003 Tokachi-oki earthquake determined by joint inversion of teleseismic body wave and strong ground motion data, Earth Planets Space, 56, 311-316, 2004.

Yagi, Y. and M. Kikuchi, Partitioning between seismogenic and aseismic slip as highlighted from slow slip events in Hyuga-nada, Japan, Geophys. Res. Lett., 30, doi:10.1029.2002GL015664, 2003.

Yokota, H., S. Kataoka, T. Tanaka, and S. Yoshizawa, Estimation of longperiod ground motion of the 1923 Great Kanto earthquake, J. Struct. Constr. Eng., Architectural Inst. Japan, 401, 35-45, 1989 (in Japanese with English abstract).

Yoshida, S. and K. Koketsu, Simultaneous inversion of waveform and geodetic data for the rupture process of the 1984 Naganoken-Seibu, Japan, earthquake, Geophys. J. Int., 103, 355-362, 1990.

Yoshida, S., K. Koketsu, B. Shibazaki, T. Sagiya, T. Kato, and Y. Yoshida, Joint inversion of near- and far-field waveforms and geodetic data for the rupture process of the 1995 Kobe earthquake, J. Phys. Earth, 44, 437-454, 1996.

Zhu, L. and L. A. Rivera, A note on the dynamic and static displacements from a point source in multilayered media, Geophys. J. Int., 148, 619$627,2002$.

R. Kobayashi (e-mail: reiji@eri.u-tokyo.ac.jp) and K. Koketsu 